\title{
DESENVOLVIMENTO DE PRODUTOS SUSTENTÁVEIS, A PARTIR DAS RELAÇÕES ENTRE DESIGN UNIVERSAL E ECODESIGN
}

\author{
Vicente Cerqueira, Dr. (UFRJ); Lisandra Rodriguez, (UFRJ); João \\ Vitor Laureano, (UFRJ); Luiza Villapouca, (UFRJ).
}

\author{
PALAVRAS CHAVE \\ Inovação Socioambiental; Design Universal; Concepção de Produtos; Ecodesign
}

KEYWORDS:

Environmental innovation; Universal Design; Concept of Projects; Ecodesign;

\section{RESUMO}

O presente artigo é resultado de estudos de iniciação científica realizados no período entre 2013 e 2015 e discute como as ações em design universal corroboram a sustentabilidade, a partir de soluções técnico-produtivas compatíveis com as práticas do Ecodesign. Logo, o objetivo central consiste em estabelecer nexos entre ações em Design Universal com as atividades intrínsecas à responsabilidade socioambiental, visando estabelecer um paralelo conceitual para a concepção de projetos de produtos, sistemas e ambientes. A metodologia adotou a análise comparativa de base qualitativa, a partir de projetos acadêmicos e produtos comercializados, a fim de verificar pontos de convergência entre agregação de valores sociais e ecológicos. Como resultado foi possível observar nas amostras que os preceitos do Design Universal são compatíveis com a sustentabilidade técnico-produtiva, com destaque para o aumento do ciclo de vida, a redução de insumos, a flexibilização produtiva entre outros aspectos que agregam valores significativos para o bem-estar social. Abstract

This article is the result of scientific research studies conducted in the period between 2013 and 2015 and discusses how actions in universal design contributes to sustainability, from technical-productive solutions compatible with the Ecodesign practices. Therefore, the central aim is to establish links between actions on Universal Design with intrinsic activities to social and environmental responsibility, to establish a conceptual parallel to the design of product designs, spaces and systems. The methodology used comparative analysis of qualitative basis from academic projects and marketed products in order to verify points of convergence between aggregation of social and ecological values. As a result it was observed in the projects and products analyzed, that having used the principles of Universal Design, the presence of various elements compatible with the technical and production sustainability, such as: increased life cycle, reduction of inputs, productive flexibility among others that add significant value to social welfare. 


\section{INTRODUÇÃO}

Grande parte dos produtos, sistemas e ambientes é pensada utilizando determinados critérios de marketing, principalmente aqueles baseados em segmentação de mercado, a partir da definição de grupos de usuários e perfis de consumo. De certo modo, a segmentação de mercado é uma importante ferramenta para se entender as relações de consumo e as expectativas que poderão identificar novos valores aos produtos, ambientes e serviços. Entretanto, a segmentação faz referência a grupos sociais com maior potencialidade econômica, excluindo grupos que, por algum motivo, não estão qualificados para a geração de novos atributos funcionais.

Esta visão estabelece à maioria dos produtos, ambientes e serviços uma percepção satisfatória para a maioria da sociedade, do ponto de vista funcional, usual, formal e até mesmo ambiental, com destaque para aqueles que são utilizados no dia-a-dia, isto é, os denominados objetos do cotidiano. Porém, nos últimos anos esta percepção vem se alterando a partir dos conceitos de sociedade inclusiva e de sociedade sustentável, estabelecendo, novas conotações aos produtos industriais em relação a uma sociedade mais justa e ética. Esta percepção sobre as condições de usos são decorrentes de vários aspectos, sendo o principal, a crença na capacidade adaptativa do ser humano. Entretanto, como exigir que uma pessoa com 75 anos tenha a mesma mobilidade ao subir uma escada? Qual o conforto de uma pessoa obesa em uma poltrona de avião? Como uma criança cadeirante consegue interagir com outras em um playground escolar? Como um deficiente visual (não necessariamente cego) consegue ter um modo de vida independente? E podemos incorporar ainda outra conotação: Há sustentabilidade sem inclusão social?

Essas perguntas fogem do controle da maioria das pessoas ou, de algum modo, são ignoradas, pois refletem atividades rotineiras e que, normalmente, são respondidas de maneira evasiva, do tipo "dar-se um jeito", "é assim mesmo...", "não é sempre que se usa..." entre outras que dificultam as relações ao estabelecerem distinções sociais. Essas questões, a princípio, estão baseadas na condição física, todavia, acabam por interferir em condições sociais e psicológicas resultantes do processo gradativo de exclusão do convívio social e da negativa de Bem-estar. Assim considera-se que a um dos principais preceitos para a sustentabilidade é a inclusão social como forma de interação de diversos aspectos que estabelecem o processo civilizatório compatível com o momento atual.

Tendo em vista a escassez de estudos relacionados à temática do Design Universal na concepção de produtos, propôs-se uma pesquisa de iniciação científica, na Universidade Federal do Rio de janeiro - UFRJ, destinada ao estudo e à proposição de um método de abordagem para a concepção de produtos industriais a partir dos preceitos do Design Universal. Após o desenvolvimento dos primeiros estudos foi identificado que as ações projetivas baseadas no Design Universal corroboram diretamente com a sustentabilidade produtiva, tendo como referência os princípios do Ecodesign e da responsabilidade socioambiental. A partir dessa prerrogativa, se determinou uma vertente para a pesquisa, isto é: o Design Universal é sustentável? Para responder a este questionamento foram realizadas análises criticas em projetos acadêmicos e produtos comercializados que estejam focados nas diretrizes do Design Universal.

Logo, o objetivo central deste trabalho consiste em estabelecer parâmetros que relacionam as proposições do Design Universal com o Ecodesign, a partir princípio da sustentabilidade técnico-produtiva, como forma de ação estratégica para o desenvolvimento de produtos, ambientes e sistemas que possam oferecer melhorias na qualidade de vida e inclusão social. Essa pesquisa foi iniciada em agosto de 2013 e encontra-se em faze final e com previsão de término para junho de 2016, onde se espera apresentar um método de análise e desenvolvimento de conceitos projetivos que integre grupos sociais distintos a partir dos preceitos do Design Universal.

Apesar dos estudos se centrarem nos aspectos relacionados ao Design Universal, considera-se, conforme já comentado, que este enfoque contribui, de maneira significativa com as ações aplicadas à responsabilidade socioambiental e às estratégias de sustentabilidade produtiva, pois além de estabelecer valores expressivos à pessoa portadora de alguma necessidade especial (cadeirantes, obesos, idosos, gestantes, anãos, entre outros) observa-se, também, que apresenta valores expressivos em relação à ampliação do ciclo de vida, à redução de insumos e à flexibilização produtiva. Assim, o Design Universal se constitui como uma estratégia de concepção de projetos que atribui novas funcionalidades aos produtos, aos ambientes e aos sistemas, possibilitando a ampliação da usabilidade e acessibilidade intrínseca, sem com isso estabelecer 
diferenças significativas do ponto de vista formal, dimensional e utilitária, oferecendo, assim, plenas condições de Bem-estar pela integração e inclusão social.

\section{CONTEXTO HISTÓRICO}

O Design Universal, também denominado de 'design total' ou 'design inclusivo', corresponde à concepção e desenvolvimento de projetos que visa ampliar a abrangência usual de produtos, ambientes e serviços, tendo como referência principal a integração de diversos grupos sociais, visando com isso à eliminação das barreiras tecnológicas existentes nos ambientes domésticos, profissionais ou mesmo sociais. Este modo de concepção de projetos tem como objetivo estabelecer soluções tecnológicas que possibilitem a inclusão social de indivíduos portadores de alguma limitação física, sensorial, psicológica ou até mesmo sociológica, tanto de modo permanente quanto momentâneo, sem com isso estabelecer diferenças expressivas aos aspectos formais e funcionais.

A partir de uma contextualização histórica, verifica-se que as ações referentes ao Design Universal tiveram início na década de 1960, em países como EUA, Inglaterra, Japão, Itália e Suécia que perceberam demandas sociais a cerca da inclusão de pessoas portadoras de algum tipo de deficiência física ou mental. Tanto assim, que em 1960 foi realizada a primeira paraolimpíada, em Roma, como forma de estimular o convívio e as relações sociais e entre as proposições iniciais destacavam-se aquelas relacionadas à adequação dos espaços e dimensionamentos de instalações arquitetônicas e urbanísticas existentes.

Em paralelo a essas iniciativas, começam a surgir críticas aos modelos de produção em massa e, por conseguinte, a maneira como os objetos são concebidos. Vários filósofos, sociólogos e designers observam que cultura de massas atende, principalmente, às necessidades dos setores produtivos por meio da padronização do comportamento social, ignorando grupos minoritários ou com pouca expressividade econômica. Esta maneira de concepção determinaria a exclusão de vários grupos sociais do acesso às tecnologias e aos bens manufaturados. Marcuse (1966), por exemplo, preconizou as bases para uma nova percepção social, a partir da mudança nas relações econômico-produtivas estabelecidas pela sociedade industrial e sua condição de alienação das necessidades individuais e ambientais, propondo novos cenários produtivos e econômicos que considerassem as individualidades como base para uma sociedade mais equilibrada em suas expectativas e necessidades.
Algumas dessas propostas se converteriam em soluções projetivas nas décadas seguintes. Entretanto, grande parte das conquistas tecnológicas ainda se concentrava na incrementação dos processos produtivos e, apenas em finais da década de 1970, é que a produção uniformizadora, sede espaços para o desenvolvimento de novas estratégias, redirecionado a produção em massa para sistemas mais flexíveis que comportam elementos diferenciadores desde a concepção projetiva e produtiva. Apesar de diversas iniciativas, como o 'toytismo', a indústria ainda ignorava outros segmentos sociais, em destaque aqueles relacionados aos portadores de necessidades especiais como um grupo com potencialidades econômicas.

Ao considerar os fatores de marketing como norteadores de estratégias, observa-se que durante a transição das décadas de 1970 e de 1980, a principal estratégia das empresas passou a ser direcionadas aos produtos, ocasionado novas percepções quanto às relações de uso e, consequentemente, de consumo. Entre as principais contribuições do 'Marketing de Produtos' esta a segmentação de mercado que permitiu maior compreensão das diferentes perspectivas relacionadas à maneira como se estabelece a relação de consumo em grupos sociais, assim como na maneira como os projetos são concebidos. Como exemplo, citam-se produtos adaptados ou projetados para o segmento de canhotos, evolução tecnológica de cadeiras de roda, utilidades domésticas para cegos entre outros. Porém, as proposições referentes ao Design Universal só seriam efetivamente implementadas em meados da década de 1980, a partir das contribuições de Donald Norman e Ronald Mace.

Norman (1985) ao desenvolver estudos no campo da psicologia cognitiva aliada aos conceitos da usabilidade teceu críticas à maneira como os objetos e as cidades são desenvolvidas e, por conseguinte, estabeleceu as bases para um design centrado nas necessidades humanas - user centered design - destacando que os objetos e ambientes são, na realidade, mediadores sociais e, como tal, devem adquirir aspectos para a inclusão social, por meio de uma percepção qualitativa que considera a diversidade de perfis como aspectos fundamentais para o desenvolvimento social.

Por sua vez, Mace (1988) demonstrou como as cidades e os objetos que às compõem são excludentes aos indivíduos portadores de alguma limi- 
tação física e, após estudos práticos no âmbito dos ambientes e sistemas, estabeleceu as bases para a elaboração de projetos inclusivos, focados, principalmente, na integração de portadores de necessidades especiais com usuários de modo geral. Porém, suas críticas não se restringiram à concepção dos ambientes sociais, mas, também, como os produtos e serviços possuem aspectos impedidores à inclusão social, independentes da idade, da habilidade ou das circunstâncias de vida. Mace saliente que o paradigma da inclusão social no acesso/uso de produtos específicos (cadeira de rodas, próteses, entre outros) não garante o convívio social, destacando que o foco do Design Universal é mais abrangente, pois não se limita às adequações, mas sim a um conjunto de percepções projetivas que buscam desenvolver qualidade de vida por meio de novos atributos funcionais, visando com isso atingir um amplo espectro de usuários, sem estabelecer alguma distinção sobre as condições de uso ou acesso, gerando plena integração social.

Os estudos coordenados por Mace, no Center for Universal Design, localizado na North Carolina State University propõe sete diretrizes básicas para a concepção de projeto/produto que tenha características em Design Universal, tais sejam:

1. Aplicação equitativa: o produto deve considerar seu uso por pessoas com habilidades e condições diversas;

2. Aplicação Flexível: o produto deve ampliar a faixa de perfis de uso, considerando, inclusive, condições sociais, culturais e ambientais;

3. Aplicação simples e intuitiva: o produto deve ser de fácil compreensão, independente da experiência, conhecimento, linguagem ou nível de concentração do usuário;

4. Aplicação de informação de fácil percepção: o produto deve conter informações necessárias para o usuário, independente de suas habilidades ou condições sensórias, culturais e ambientais;

5. Aplicação de tolerância ao erro: o produto deve minimizar ao máximo os riscos e consequências adversas de ações acidentais ou não intencionais;

6. Aplicação de baixo esforço físico: o produto deve oferecer condições de eficiência, conforto e adequação com o mínimo de esforço físico;

7. Aplicação de dimensões e espaço ao uso: o produto deve oferecer condições de acesso, ajustes, alcance, manipulação e uso independente do tamanho, postura ou mobilidade.

Logo, considerando as proposições verificase que, de modo geral, a atenção básica do Design Universal esta na elaboração de soluções tecnológicas que permita o pleno convívio social de grupos portadores de necessidades especiais com outros segmentos sociais, sem estabelecer diferenças significativas nas características formais, usuais e dimensionais apresentadas pelos produtos, ambientes ou sistemas, estabelecendo, assim, condições de Bem-estar físico, psicológico ou até mesmo econômico. A Figura 01 mostra as relações necessárias para o entendimento de questões relacionadas ao convívio social e integração nos ambientes, definidos por parâmetros de acessibilidade e de usabilidade mediados pela mobilidade.

A acessibilidade expressa no ambiente externo sejam públicos ou privados, permite que pessoas com deficiências ou reduções físicas e sensoriais participem de atividades rotineiras que incluem o uso de produtos e sistemas. Apesar da extensão aplicativa do termo acessibilidade, este tem sido mais comumente aplicado aos projetos de arquitetura e urbanismo, como forma de possibilitar a mobilidade no espaço urbano, por meio da eliminação de obstáculos e na adaptação da infraestrutura. Já o termo usabilidade é definido em ergonomia para qualificar a interação entre pessoas com produtos e sistemas, durante a realização de determinadas tarefas (Moraes, 2006). Entretanto, verifica-se que este termo é mais empregado para mensurar aspectos na relação Homem-computador, assim como nas interfaces de comunicação e informação ou ainda subsidiar o desenvolvimento de tecnologias assistivas. O Design Universal considera os aspectos citados acima, mas estabelece uma nova dinâmica interativa nos objetos presentes tanto nos ambientes internos (residências, escolas, locais de trabalho, entretenimentos, entre outros) com os ambientes externos (ruas e vias públicas e privadas, sistema de transporte, praças e mobiliários urbanos, entre outros) a partir da mobilidade e da possibilidade de integração social, sendo assim possuem componentes que interagem tanto aspectos da acessibilidade quanto da usabilidade para permitir a plena mobilidade social. 
Figura 01- Sistema integrado em Design Universal para ambientes de convívio.

\section{SISTEMA PARA INCLUSĀO SOCIAL}

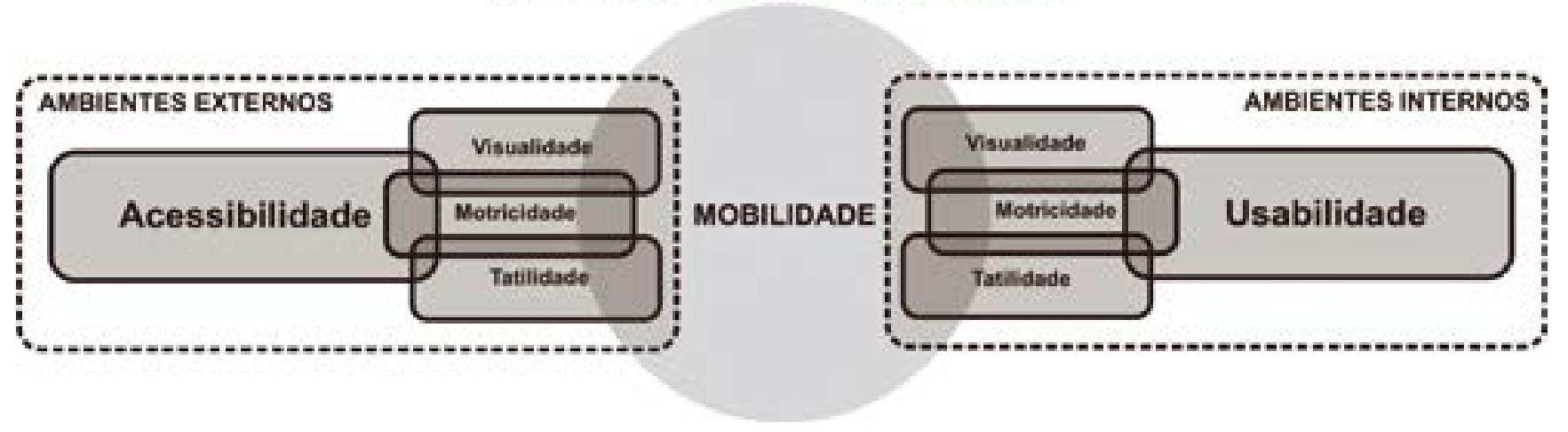

Fonte: Autores

\subsection{RELAÇÕES ENTRE ERGONOMIA, DESENHO UNIVERSAL E DESIGN UNIVERSAL.}

De certo modo, pode-se questionar quais os elementos diferenciadores da abordagem em Design Universal dos estudos da ergonomia. De acordo com McCormick (1980) entre outros, a ergonomia é definida como uma tecnologia destinada ao aperfeiçoamento das relações humanas com produtos, ambientes e sistemas. Para tal, baseia-se em um conjunto de conhecimentos, que inclui a antropometria, a biomecânica, a fisiologia e a psicologia, visando à especificação de parâmetros ao desenvolvimento de projetos tornando-os compatíveis às necessidades e limitações das pessoas em relação à atividade produtiva.

No campo da antropometria, Panero \& Zelnik (1982) e Neufert (1999) desenvolveram uma série de estudos ergonômicos destinados ao dimensionamento de espaços adequados a cadeirantes e pessoas como mobilidade reduzida em ambientes internos e que permitem a acessibilidade nos ambientes externos. Apesar das especificações, observa-se que as propostas são insuficientes, do ponto de vista metodológico, para qualificar projetos de produtos, ambientes e sistemas dentro dos princípios do Design Universal, pois se apresentam de maneira limitada aos aspectos dimensionais da forma ou de espaços.

Mas recentemente, Cambiaghi (2012) elencou uma série de dados e informações que especificam parâmetros para o desenvolvimento da acessibilidade em ambientes internos e externos. A partir de diversos estudos de casos são estabelecidas críticas e demonstrado como 'desenhar' adequadamente as instalações e os ambientes, a fim de permitir a inclusão social de indivíduos portadores de atenção especial, sejam eles deficientes, idosos ou portadores de algum tipo de impedimento motor ou sensorial. Grande parte das proposições apresentadas leva em consideração dados antropométricos ou indicativos para adaptações, tendo como finalidade a incorporação de recursos facilitadores em produtos ou para adequação de espaços.

Por outro lado, o uso da ergonomia contribui para o desenvolvimento de projetos, a partir da elaboração/ definição de indicativos físicos e/ou sensoriais sobre a estrutura da operação necessária ao uso de produtos, ambientes e sistemas, permitindo, assim, sua 'quantificação dimensional'. Ainda no campo dimensional citam-se os aspectos relacionados aos denominados 'fatores humanos'. Em linhas gerais, este conceito se refere às propriedades físicas, cognitivas e até mesmo culturais presentes no comportamento individual e social e que podem influenciar os sistemas tecnológicos. Por este motivo alguns autores, de base projetual defendem a ideia de que fatores humanos e ergonomia são sinônimos aplicativos, enquanto outros, principalmente, aqueles de base psicológica observam diferenças quanto ao método de abordagem e aplicação.

No entanto, salienta-se que a validação dimensional deverá estar apoiada na 'qualificação conceitual', por meio da proposta projetiva, conforme exemplificado na Figura 2. Onde os autores do projeto, por meio da elaboração do mapa de avanço/alcance, compatibilizaram dados antropométricos com as operações de preparo e guarda de alimentos (aspectos culturais), gerando uma estrutura com características componíveis não modular, adequada a diversos tipos de residências qualificadas como populares referendadas pelo programa "Minha casa minha vida". A partir daí, pode-se se definir locais e volumes necessários à guarda e ao armazenamento de produtos e objetos utilitários, validando, assim, a proposta conceitual baseada nos princípios do Design Universal. 
Figura 2- Mapa de avanço/alcance destinado ao dimensionamento de acesso.

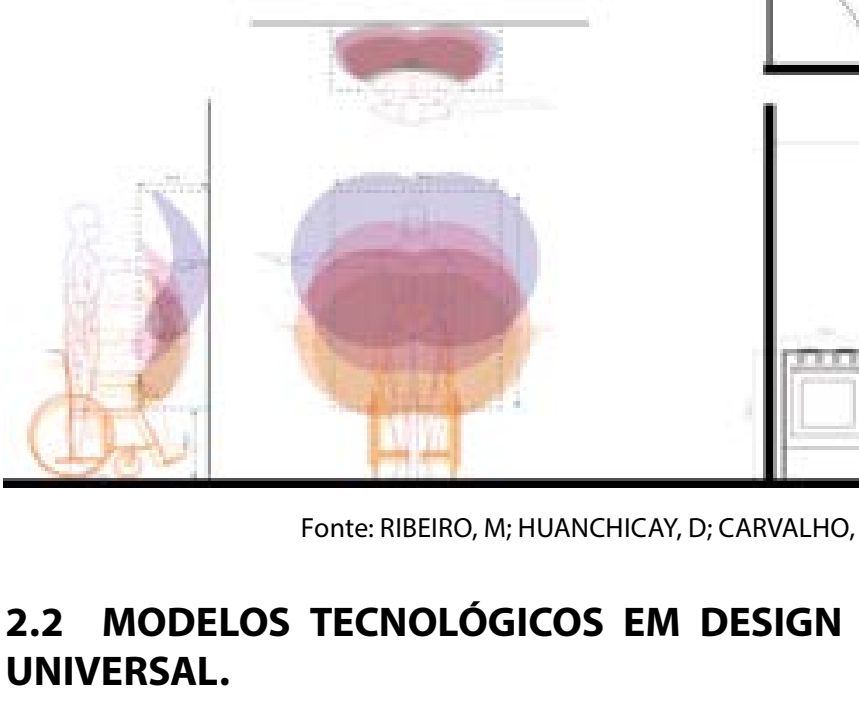

Outro ponto verificado no estudo se refere à tipologia aplicada aos projetos e produtos que enfocam a acessibilidade como recurso de inclusão social. Durante o levantamento foram identificadas quatro categorias tecnológicas que oferecem soluções para a inclusão social de portadores de algum tipo de deficiência física, sensorial e intelectual. Contudo, durante esses estudos, foi observada (ainda de maneira básica) a existência de determinada condição humana que limita ou determina a perda da capacidade motora, sensorial e intelectual e que condicionam novos requisitos projetivos, isto é a 'Depressão'.

Parte deste grupo de 'deficiências' foi identificada por Donald Norman ao se referir aos aspectos cognitivos presentes nos objetos e que determinam barreiras invisíveis de uso. Logo, para este estudo foi incorporado um oitavo princípio aos parâmetros do Design Universal, isto é: 'Aplicação cognitiva': o produto deve oferecer estímulos positivos ao seu uso, evitando barreiras tecnológicas que desfavoreçam sua compreensão quanto à sua utilidade.

Deste modo, foram identificados os seguintes grupos tecnológicos aplicados às soluções projetivas em Design Universal e que contribuem para a inclusão social:

Deste modo, foram identificados os seguintes grupos tecnológicos aplicados às soluções projetivas em Design Universal e que contribuem para a inclusão social:

- Design adaptativo: tecnologias aplicadas para adequar produtos em geral aos portadores de necessidades especiais, sem com isso perder sua característica funcional básica;

- Design assistivo: tecnologias destinadas à melhoria das condições de vida da pessoa portadora de necessidades especiais mediante produtos de uso específicos;

- Design inclusivo: tecnologias destinadas à inserção de grupos sociais formados ou não por portadores de necessidades especiais no cenário econômico e produtivo;

- Design 'apropriado': tecnologias que visam atender a determinados grupos sociais ou mesmo indivíduos, podendo ser aplicada ou não a portadores de necessidades especiais.

Além das categorias tecnológicas aplicadas ao Design Universal, existem outros dois enfoques que corroboram com as práticas presentes no Ecodesign. Segundo Manzini \& Vezzoli (2002), o Ecodesign corresponde à atividade projetiva que associa aspectos tecnológicos aos ecológicos, visando o desenvolvimento de 'soluções integradas às questões sociais' e que sejam 'aceitáveis do ponto de vista cultural'. Entre os principais atributos estabelecidos pelo Ecodesign destacam-se os seguintes: Utilização de poucas tecnologias na fabricação; Seleção de materiais com facilidade de reciclagem; Normalizações e procedimentos técnicos; Elaboração de planos de incentivos ao retorno de produtos (logística reversa); Aumento da qualidade e durabilidade de produtos; e a 'Inserção social a partir de princípios éticos', entre outros. Portanto, o Ecodesign corresponde a uma ferramenta de gestão do design que agrega valor competitivo aos produtos, ambientes e sistemas 
Figura 3 (A e B)- Carteira Escolar Inclusiva - CEl com regulagens na cadeira e mesa adequando o produto a diversas necessidades e fases do usuário - Projeto do Estúdio Índio da Costa Design em parceria com a ONG Noisinho da Silva.

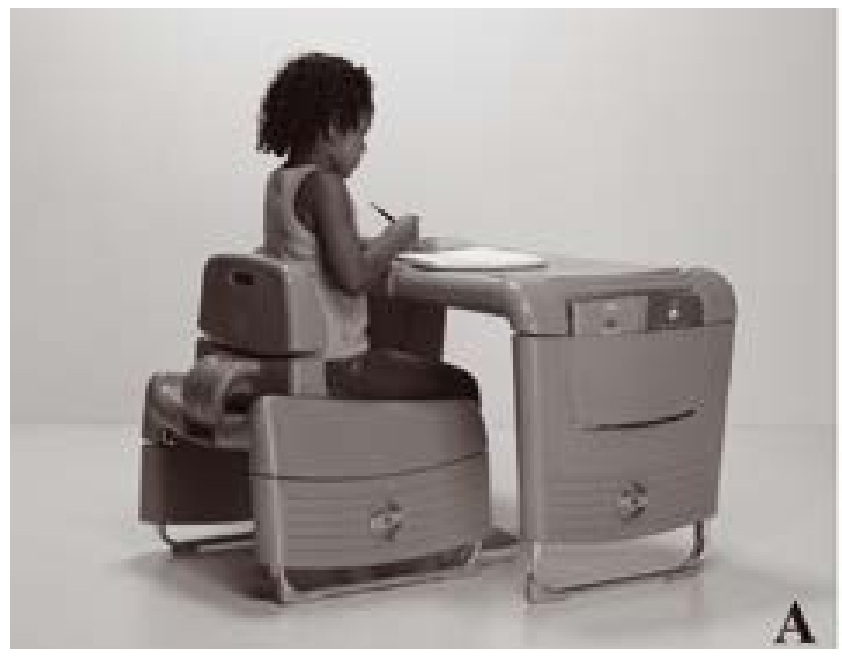

por novos modelos de produção, distribuição e consumo, contribuindo, deste modo, para o desenvolvimento sustentável. Ainda neste contexto, verificam-se dois aspectos tecnológicos de significativa importância para o Ecodesign e que estão presentes no Design Universal, tais sejam: o ciclo de vida e a flexibilização produtiva.

De modo geral, a análise do ciclo de vida tem sido estudada, a partir de modelos que determinam maior rentabilidade econômica. Porém, ultimamente tem-se incorporado ao ciclo de vida conceitos do Ecodesign. A atual avaliação do ciclo de vida leva em consideração todos os impactos ocasionados pelo processo produtivo, ou seja, sua história desde as fases iniciais de obtenção de matérias-primas até as fases relacionadas ao descarte e reaproveitamento. Segunda a Associação Brasileira de Ciclo de Vida (ABCV) este conceito é definido como “... uma técnica que estuda os aspectos ambientais e os impactos potenciais (positivos e negativos) ao longo da vida de um produto ou serviço...", permitindo a mensuração da sustentabilidade, a partir de informações socioambientais. Curiosamente, este princípio foi destacado por Ronald Mace em artigo intitulado The home to all life with welfare, que indica como Design Universal contribui com o aumento do ciclo de vida dos produtos. A Figura 3 (A-B) exemplifica como determinadas soluções em Design Universal contribuem para o aumento do ciclo de vida.

O outro enfoque tecnológico que se integra aos conceitos do Design Universal e do Ecodesign é a 'produção flexível'. A partir da década de 1970, o sistema de produção em massa, cedeu espaço ao sistema de produção flexível, como resposta

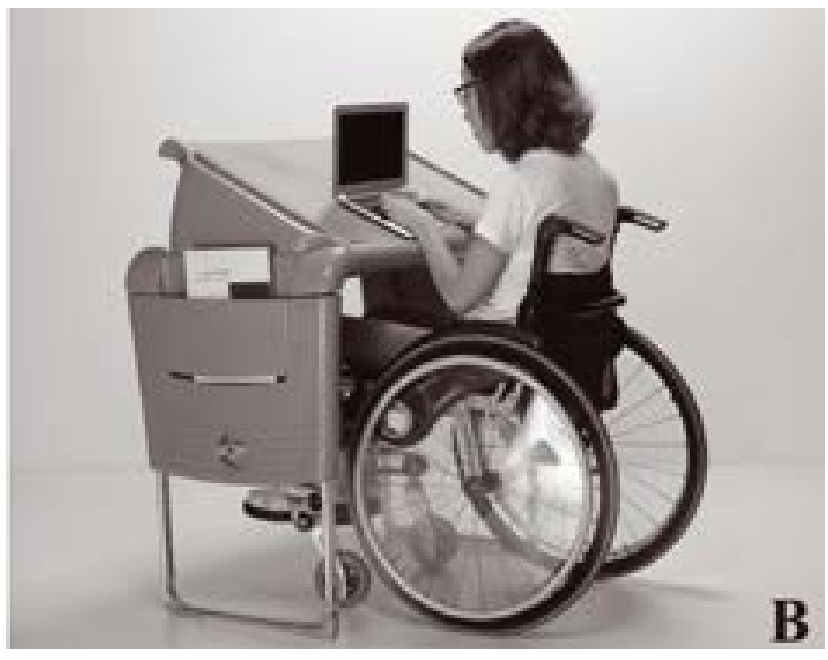

Fonte: Instituto Noisinho da Silva, 2014; Foto: Eugênio Sávio

aos problemas relacionados tanto à produção, quanto às expectativas dos consumidores. A partir do 'toyotismo', os sistemas de produção deixaram de se concentrar na quantidade produzida para focar na qualidade ofertada. De certo que esta mudança de ótica alterou, significativamente, os aspectos de concepção de projetos, pois se concentraram nas novas demandas dos consumidores. Entre os principais pontos presentes neste tipo de produção estão: a redução dos estoques e suprimentos; a simplificação dos projetos; a melhoria do sistema de qualidade entre outros, que determinaram um novo perfil ao sistema de produção mundial. A Figura 4 mostra conjunto de panelas destinadas às pessoas portadoras de cegueira ou com visão reduzida. As peças que compõem o conjunto são intercambiáveis, possibilitando arranjos e combinações distintas, além de facilitar seu uso por meio de pegas simples e uso induzido.

\subsection{INCLUSÃO SOCIAL E RESPONSABILIDADE AMBIENTAL.}

No tópico anterior foram relacionados diversos fatores e aspectos que estão presentes nos atributos funcionais do Design Universal e que determinam o Bem-estar e a inclusão social, onde os produtos, ambiente e sistemas devem ser concebidos dentro de uma ótica mediadora entre usuário, função e sociedade. Neste contexto, surgem aspectos que determinam fatores sustentáveis, em especial os referentes à responsabilidade social. Isto porque, se de um lado busca-se a inclusão social por meio dos projetos; do outro lado, verifica-se a necessidade de integração ambiental por meio dos processos produtivos. 
Figura 4 (A e B)- Conjunto de panelas para portadores de necessidades especiais, baseado em dietas alimentares.
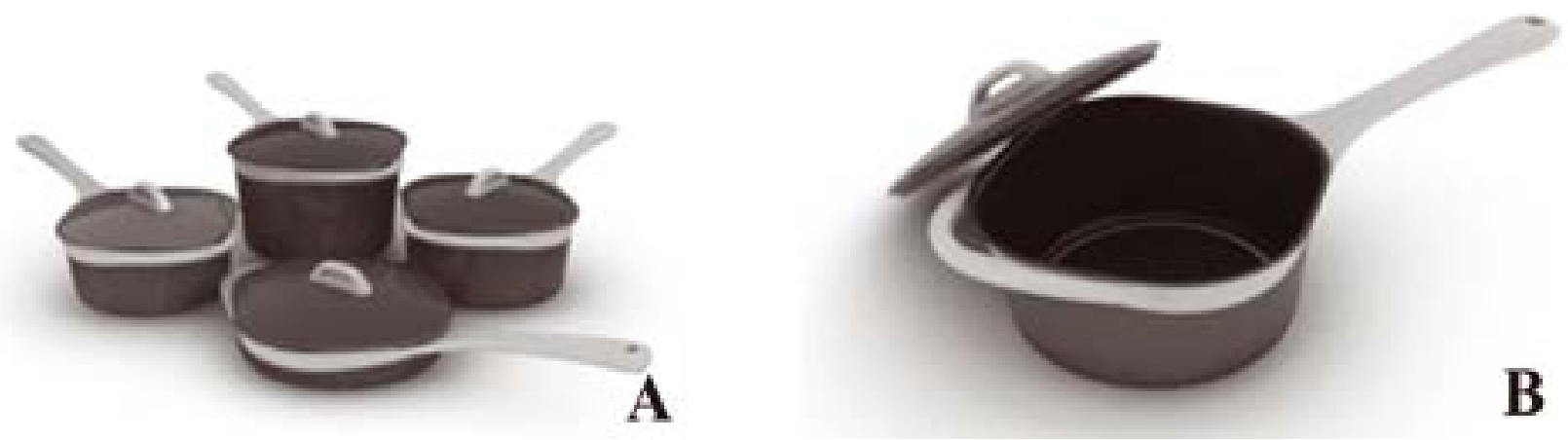

Fonte: FERREIRA, M. - Monografia de PGDI - Publicação Interna. Rio de janeiro: EBA/UFRJ, 2008

Atualmente, os aspectos ambientais são de suma importância para o desenvolvimento econômico e social, pois contribuem com ganhos na qualidade de vida mediante diversos fatores de base econômica, tecnológicas ou ecológicas. Sendo assim, meio ambiente e o bem estar social (e individual) são conceitos indissolúveis, ou seja, tangem à responsabilidade socioambiental. Verifica-se, no entanto, que as orientações normativas e legislativas, apesar de citarem a inclusão social como atributo da sustentabilidade, não se apresenta de modo direto aos procedimentos de integração de portadores de atenção especial com o escopo da sociedade. Porém, observam-se diversos pontos convergentes, que fazem menção à integração dos macros-conceitos ambientais e sociais. A série NBR 16000 (2004-2012), destinada à Responsabilidade Social, relaciona a gestão ambiental, a saúde e o Bem-estar da sociedade, determinando às empresas e aos governos ações no âmbito social e ambiental, como forma de interagir programas de desenvolvimento com economia sustentável. Por outro lado, a legislação brasileira que estabelece os direitos das pessoas portadoras de necessidades especiais (Lei No 6949/2009), destaca atenção à geração de rende deste grupo social como forma de garantir acesso à melhoria da qualidade de vida e a dignidade humana.

De certo que a normatização, é referente aos fatores e aspectos que incidem sobre sistemas produtivos e seus impactos ambientais no compito da sociedade. Todavia, percebe-se que as referências ambientais estão expostas ao lado de diversos indicativos sociais que definem metas em função dos Direitos Humanos (Caetano et all, 2007). E é neste sentido que as práticas da sustentabilidade deverão observar, também, a inclusão social de grupos sociais merecedores de atenção especial, como forma de se estabelecer uma sociedade mais justa, ética e equânime em seus direitos. Logo, considerando que as iniciativas em benefício da sociedade e do meio ambiente, visam o pleno desenvolvimento humano, defende-se a inclusão dos portadores de necessidades especiais como parte integrante dos princípios de sustentabilidade econômico-produtiva, pois a responsabilidade socioambiental deve ser percebida através da plena condição de Bem-estar entre os grupos sociais. A Figura 5 exemplifica outra estratégia compatível com o Ecodesign e que corrobora com as ações de inclusão social. As peças que compõem os brinquedos são todas produzidas por rotomoldagem em polietileno de alta densidade (HDPE), com enxertos estruturais em aço-carbono estampados. As soluções mecânicas são intercambiáveis, o que possibilita, em caso de dano físico, a reposição de apenas partes do conjunto, assim como facilita o uso da logística inversa ou o processo seletivo para reciclagem, por utilizar poucas tecnologias na fabricação dos componentes mecânicos.

Figura 5- Playground Universal produzidos com poucos processos produtivos, visando o convívio lúdico e participativo.

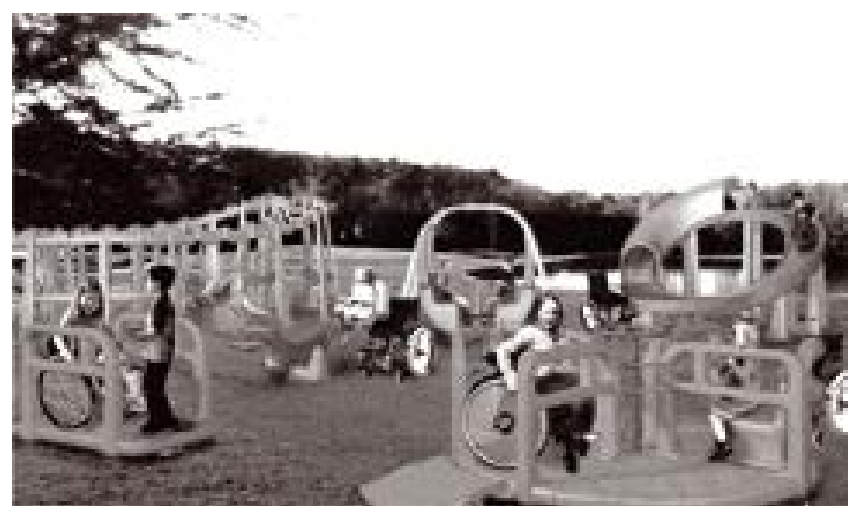

Fonte: SHAW YIE, C. - Monografia de PGDI - Publicação Interna. Rio de janeiro: EBA/UFRJ, 2007 


\section{METODOLOGIA APLICADA}

A ótica metodológica empregada, de maneira específica para este estudo teve como base a pesquisa exploratória por meio da análise comparativa, tendo como finalidade a identificação de elementos presentes em projetos e produtos desenvolvidos sobre a ótica do Design Universal e que tenham relações com a sustentabilidade técnico-produtiva, a partir dos conceitos sobre o Ecodesign e responsabilidade socioambiental. De modo geral, a pesquisa seguiu as seguintes fazes:

A. Estudos referentes à normatização e procedimentos sobre responsabilidade social e ambiental;

B. Seleção de projetos e produtos elaborados com o enfoque tecnológico do design universal para análise;

C. Classificação de tecnologias aplicadas em Design Universal e princípios tecnológicos do Ecodesign;

D. Análise e identificação de parâmetros técnicos que relacionam o design universal com a sustentabilidade técnico-produtiva;

E. Conclusão e proposta metodológica para desenvolvimento de produtos com responsabilidade socioambiental.

O estudo foi planejado utilizando projetos acadêmicos e produtos comercializados que com o enfoque do Design Universal. No grupo de projetos foram considerados 18 projetos, sendo 14 em Design e 4 em Engenharia e no grupo de produtos foram consideradas 6 amostras. A princípio não houve pré-seleção, sendo consideradas todas as amostras que se autodeclaravam projetadas utilizando princípios do Design Universal. Das 24 amostras coletadas, 5 amostras (4 projetos e 1 produto) foram descartadas, pois não continham pelos menos 3 elementos propositivos em Design Universal ou pela falta de dados que pudessem fornecer subsídios para a análise, tais como: desenhos projetivos, modelos, relatórios entre outros, ou ainda não apresentavam compreensão equivocada sobre o Design Universal, pois eram de uso exclusivo para portadores de necessidades especiais.

Em função do número de amostras, adotou-se pensamento de base qualitativa para análise. Foi elaborada uma ficha contendo 20 parâmetros-itens, sendo 10 perguntas relacionadas ao Design Universal para validar a amostra e 10 itens relacionados ao Ecodesign. Cada parâmetro-item considerou 3 níveis de qualidade: 1- razoável, 3-bom e 5-excelente, a fim de mensurar as amostras de. Com os dados gerados, foi possível tabular quais os projetos e produtos que apresentam soluções compatíveis ao Design Universal e simultaneamente ao Ecodesign.

\section{RESULADOS E DISCUSSÕES}

A partir dos estudos realizados foi possível, primeiramente, foram estabelecer as diferenças entre o conceito de 'Desenho Universal' e 'Design Universal', conforme demostrado na figura 6 . Alguns dos projetos e produtos analisados remetem a adequação de forma e dimensão ou são de uso específico (no caso produtos ortopédicos), não estando qualificados como exemplos em Design Universal, mesmo que estejam relacionados à inclusão social. Assim, o enfoque projetivo do Design Universal não se limita aos estudos específicos ou a dimensionamentos, mas às decisões estratégicas que irão nortear a conceituação e desenvolvimento de soluções projetivas, com conotações bem mais abrangentes, englobando, inclusive, aspectos relacionados à sustentabilidade, enquanto o desenho universal apresenta ênfase na geometria e na adequação dimensional. A Figura 05 representa, em linhas gerais as diferenças entre Desenho e Design Universal.

Logo, as ações em Design Universal correspondem aos seguintes aspectos:

1. Incorporação de novos atributos funcionais, por meio de recursos tecnológicos inovadores;

2. Ampliação da funcionalidade, por meio da integração de novos valores à função básica do produto;

3. Integração e inclusão social, por meio de produtos, ambientes e sistemas que a forma não remeta à distinção de uso e sim na maneira de utilizá-lo;

4. Aumento da utilidade oferecida, por meio de soluções específicas às possibilidades de uso, a partir da flexibilização produtiva;

5. Bem-estar dos indivíduos, por meio da plena satisfação, a partir da diversidade de perfis de usuários;

6. Responsabilidade socioambiental, por meio de uma sociedade mais consciente das diferenças e reais necessidades sociais.

Alguns aspectos referentes à inclusão social e que, por sua vez, interferem em questões de sustentabilidade, ainda necessitam de estudos mais aprofundados, principalmente, em países em vias de desenvolvimento, isto porque determinados grupos sociais possuem determinadas peculiaridades e especificidades que remetem às condições relacionadas à distribuição de renda, ou seja, estão relacionadas aos aspectos econômico-financeiros para aquisição de produtos. Segundo dados do IBGE (2010) e nos levantamentos realizados com portadores de algum tipo de necessidade especial, pertencentes aos grupos sociais de deficientes físicos, sensoriais ou mentais, assim como idosos, demonstraram que grande parte esta na faixa de renda entre apresenta renda mensal entre 2 e 5 salários 
Figura 5- Definições conceituais sobre Desenho e Design Universal
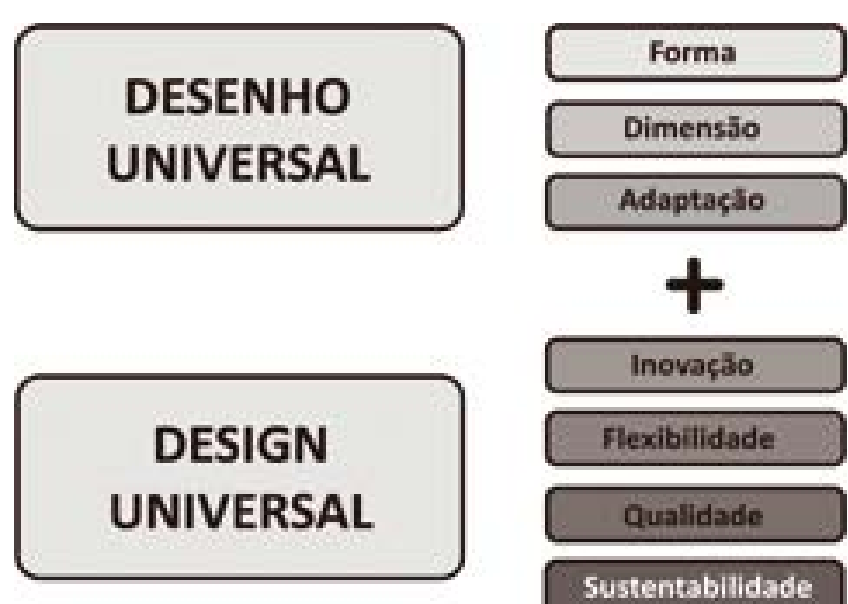

Sustentabilidade
Aplicaçăo técnica de parâmetros ergonômicoss, permitindo que Portadores de Necessidades Especiais tenham produtos adequados às suas necessidades.

Concepçăo projetiva que amplia produtos, sistemas e ambientes, por meio de nowos atributos funcionais que incluam toda sociedade, independente de suas caracteristicas pessoais. mínimos, o que limita as condições de acesso aos bens de consumo, sendo este um dado preponderando para a definição de soluções projetivas em Design Universal, pois qualquer 'sofisticação tecnológica' poderá impactar significativamente no valor final do produto ou serviço.

Mesmo havendo, em certos casos, incentivos ou renuncia fiscal, este fato deve ser observado para o desenvolvimento de projetos, para que possam ser implantados e atinjam os objetivos sociais propostos. A partir dessa premissa foram analisados alguns layouts padronizados de imóveis pertencentes ao Programa "Minha casa, minha vida", a fim de verificar as interfaces com os objetos e instalações em relação à usabilidade e mobilidade no espaço interno dessas moradias. Entre as diversas plantas de casas e de apartamentos estudados, foi possível verificar a existência de espaços inadequados ou críticos à mobilidade de portadores de necessidades especiais, a partir das condições de instalações e produtos oferecidos pelo mercado. A figura abaixo (6) mostra a planta de um apartamento unifamiliar padrão com, aproximadamente, $48 \mathrm{~m} 2$ de área total, onde a partir de objetos e instalações comuns há a ocorrência de diversos pontos críticos, principalmente, no banheiro e cozinha. Apesar das modificações ocasionais propostas para acessibilidade interna, os espaços não foram pensados tendo como parâmetros os preceitos do Design Universal.

De acordo com os estudos, foi possível identificar que os projetos e produtos analisados apresentam concepção consistente aos parâmetros em Design Universal, pois as soluções projetivas apresentadas possibilitam ações de inclusão social sem ocasionar distinção de grupos sociais, isto é, os projetos e produtos podem ser utilizados por diversos indivíduos portadores ou não de necessidades especiais. Por consequência, parte significativa das amostras, também, contribui com os preceitos do Ecodesign, pois apresenta soluções técnicas que remetem à sustentabilidade produtiva, conforme demostrado nos gráficos da Figura 7, onde $78 \%$ das amostras em projeto apresentaram soluções técnicas com índices superiores a 3 tanto nos parâmetros em Design Universal quanto nos parâmetros para o Ecodesign. Logo, pode-se qualificar que há integração de conteúdos entre os dois enfoques projetivos e que a responsabilidade social, a partir da sustentabilidade produtiva pode contribuir, significativamente, com a integração

Figura 6- O estudo de movimentos de cadeirante mostra que, partir de uso objetos de comuns, os espaços apresentam vários de pontos críticos.

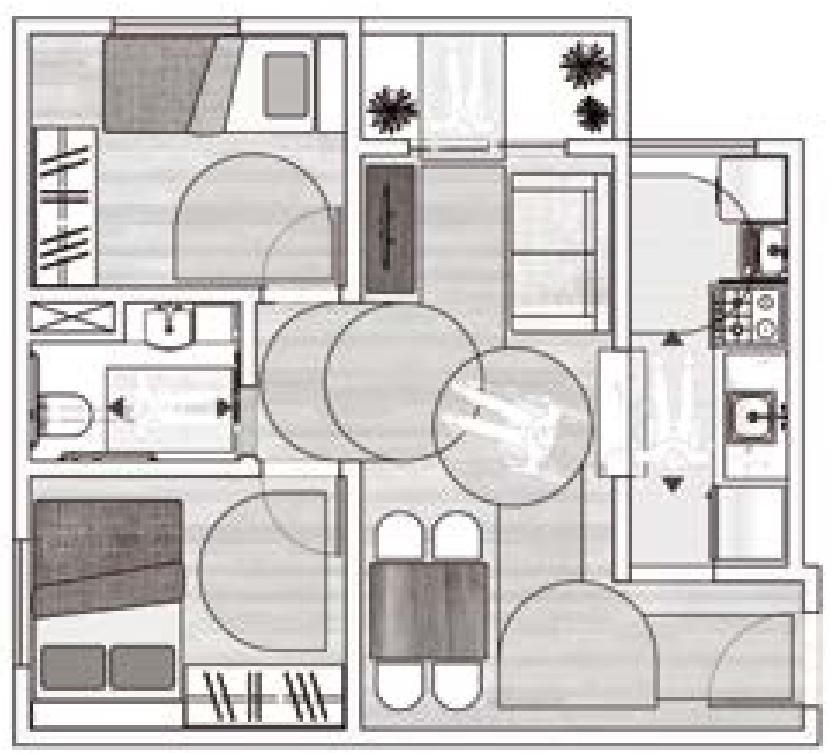

Fonte: Autores 
Figura 7- Definições conceituais sobre Desenho e Design Universal

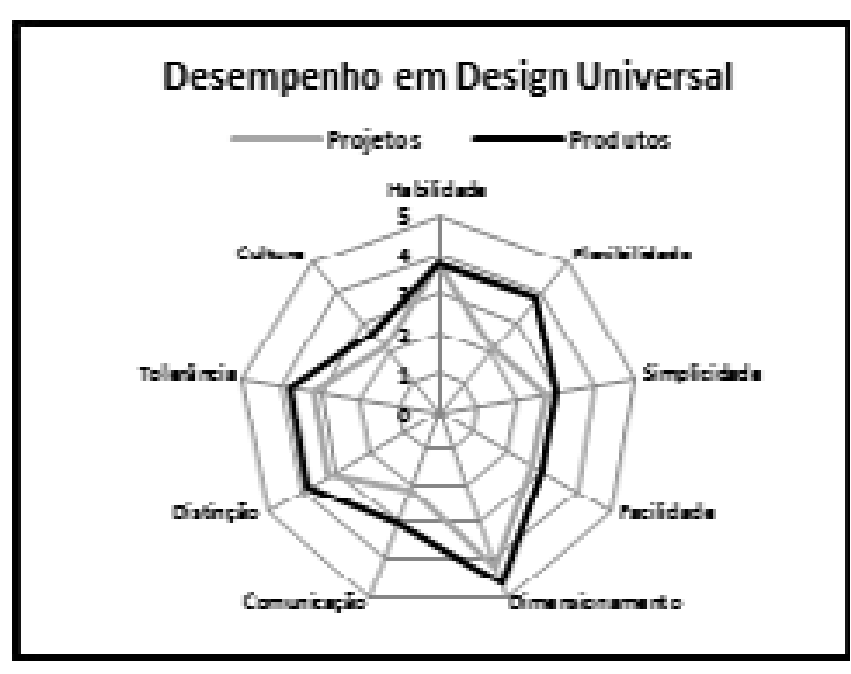

social e vice $\&$ versa. No entanto, apesar do resultado positivo - que poucas (33\% em projetos e $20 \%$ em produtos) atingiram valores médios acima do índice 4.

Logo, o Design Universal, além de se caracterizar como uma solução de inclusão social de grupos portadores de atenção especial poderá contribuir como as estratégias relacionadas ao Ecodesign, sendo capaz de mobilizar recursos tecnológicos, em decorrência da amplitude de ação em mercados, a partir de três razões: 1- Razão Sócio-Políticas; 2- Razões de Consciência Ambiental; e 3- Razões Tecnológicas. O resultado da conjugação desses três tipos de razão é que irá determinar a amplitude de ação ao projeto e que poderá condicionar ao produto o papel de mediador social e ambiental.

No âmbito, prático dos produtos não foi encontrado número significativo de amostras comercializadas com o enfoque do Design Universal, isto porque, apesar das atuais estratégicas de 'flexibilização produtiva', observa-se que o modelo de produção ainda esta baseado na produção em massa, ignorando aspectos de segmentação de grupos consumidores e, por conseguinte, desprezando necessidades específicas, em função de crenças na 'adaptabilidade dos usuários'. Isto porque, o principal foco das empresas ainda concentra-se na relação numérica obtida entre oferta versus demanda. Entretanto, cabe destacar que grande parte das soluções verificadas nos projetos e nos produtos utiliza tecnologias simples e de baixa complexidade produtiva, sem haver a necessidade de grandes investimentos tecnológicos.

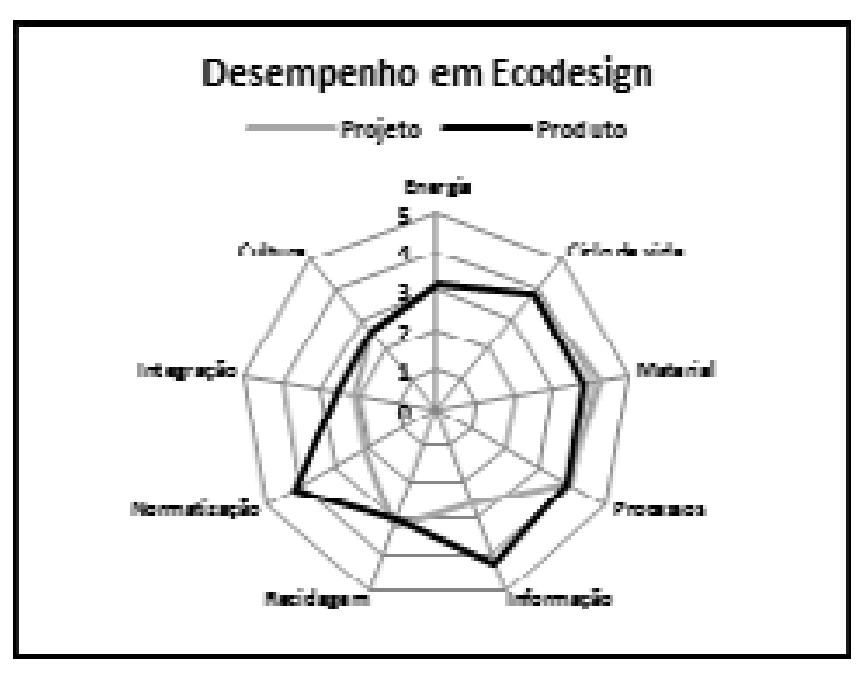

Fonte: Autores

\section{CONCLUSÃO}

Ultimamente tornou-se perceptível a crescente repercussão de conceitos relacionados à sustentabilidade e inclusão social no cenário produtivo, os quais estabelecem novos princípios tecnológicos baseados em uma sociedade mais integrada, igualitária e consciente. O presente estudo demonstrou que as ações do Design Universal convergem para conceitos relacionados com a sustentabilidade produtiva, principalmente, no que tange ao aumento do ciclo de vida dos produtos, à redução de insumos e à flexibilidade produtiva. Os projetos e produtos analisados demonstram que as diretrizes do Design Universal contribuem diretamente com as práticas do Ecodesign. Porém verifica-se que, ainda persistem dúvidas e desconhecimentos sobre as ações do Design Universal que, normalmente, é associado a conceitos opostos aos sete princípios estabelecidos. Logo, o Design Universal vem se constituindo em um importante recurso estratégico para empresas ampliar seu potencial de mercado, utilizando para isto novas percepções quanto a grupos consumidores. Assim, reafirma-se uma das principais vocações do Desenho Industrial/ Design, ou seja, exercer sua função social, através do reconhecimento que na sociedade ocorrem situações distintas e que a tecnologia deve contribuir de maneira facilitadora das relações sociais e ambientais.

Assim, o Design Universal corresponde a um método centrado no ser humano, a partir de contextualizações sociais, históricas, antropológicas, políticas, econômicas, tecnológicas e ambientais, capaz de estabelecer ao design maior interatividade entre as soluções e usos. Ou seja, é capaz de gerar uma 'filosofia estratégica' baseada na in 
serção de grupos sociais no contexto econômico e produtivo, sem com isso estabelecer qualquer tipo de barreira ou distinção. $O$ produto resultante deste processo possui atributos baseados em expectativas funcionais de maneira plena, respeitando os limites e capacidades individuais, principalmente, aquelas relacionadas às questões de acessibilidade e usabilidade, a fim de garantir condições de convívio social.

\section{REFERÊNCIAS}

1. ALMEIDA, F. Responsabilidade Social e Meio Ambiente: Os desafios da sustentabilidade. Rio de Janeiro: Elsevier, 2009;

2. BRASIL. Decreto Lei $n^{\circ} 5.296$, de $02 / 12 / 2004$. Normas gerais e critérios básicos para a promoção da acessibilidade das pessoas portadoras de deficiência ou com mobilidade reduzida, e dá outras providências. Brasília, DF, 03 dez. 2004. Disponível em: http:// legislação.planalto.gov.br. Acesso em 05 de agosto de 2013;

3. CAETANO, G.; ASHLEY, P.; GIANSANTI, R. Responsabilidade Social e Meio Ambiente. São Paulo: Saraiva 2007;

4. CAMBIAGHI, S. Desenho Industrial: Métodos e Técnicas para arquitetos e urbanistas. São Paulo: SENAC, 2012.

5. CORREA, S. Fundamentos da Biomecânica: $\mathbf{O}$ corpo em movimento. São Paulo: Ed. Mackenzie, 2014.

6. IIDA, I. Ergonomia: Projeto e Produção. São Paulo: Edgar Blücher, 1992.

7. MANZINI, E. VEZZOLI, C. O Desenvolvimento de Produtos Sustentáveis. São Paulo: EdUSP, 2002.

8. MARCUSE, H. Ideologia da Sociedade Industrial: O homem unidimensional. Rio de Janeiro: Zahar Editores, 1966.

9. MCCORMICK, E. Ergonomía: Factores humanos em Ingeniería y Diseño. Barcelona: Gustavo Gilli, 1980.

10. MORAES, A. Ergodesign do Ambiente Construído e Habitado. Rio de Janeiro: IUSER, 2005.

11. MORAES, A. Design e Avaliação de Interface. Rio de Janeiro: IUSER, 2006.

12. NEUFERT, E. A arte de Projetar em Arquitetura. São Paulo: Gustavo Gilli, 1999.
W13. NORMAN, D. The Design of everyday things. New York: Basic Book, 2002;

14. NORMAN, D. Design Emocional, por que adoramos ou detestamos os objetos do dia-a-dia. Rio de Janeiro, Rocco, 2008.

15. PALMER, C. Ergonomia. Rio de Janeiro: Editora FGV, 1976.

16. PANERO, J. \& ZELNIK, M. Las Dimensiones humanas em los espacios interiores. Barcelona: Gustavo Gilli, 1982.

17. WISNER, A. Por dentro do Trabalho. São Paulo:FTD-OBORÉ, 1987. Desenho Universal: Habitação de Interesse Social. São Paulo: CDHU.

18. Portal The Center for Universal Design: Environments and Products for All Peaple. https://www.ncsu.edu/ncsu/design/ cud/index.htm; Acesso em 23 de dezembro de 2013.

19. Portal da Acessibilidade. Secretaria Nacional de Promoção dos Direitos da Pessoa com Deficiência. Cartilha do Censo 2010: Pessoas com Deficiência. Brasília : SDH-PR/SNPD, 2012. http:// www.pessoacomdeficiencia.gov.br/app/sites/default/files/publicacoes/cartilha-censo-2010-pessoas-com-deficienciareduzido.pdf, Acesso em 20 de março de 2014.

20. Portal Revista Época. A casa para toda vida. Disponível em http://revistaepoca.globo.com/Revista/Epoca/0,EDR80173-5856,00.html; Acesso em 15 de março de 2014.

21. Portal IBGE. Censo 2010 - Pesquisa de Domićlios. Disponível em http://www.ibge.gov.br/home/estatística/população/ biblioteca.catalogo?view=detalhes\&id=2929, Acesso em 12 de abril de 2014

22. Portal Instituto Noisinho da Silva. Carteira Escolar Inclusiva CEl. Disponível em http://www.noisinhodasilva.org/\#!produtos/ c24vq; Acesso em 23 de junho de 2015.

23. Portal da Acessibilidade. Secretaria Nacional de Promoção dos Direitos da Pessoa com Deficiência. ABNT. NBR 16001: Responsabilidade social, Sistema da gestão e Requisitos. http:// www.pessoacomdeficiencia.gov.br/app/normas-abnt; Acesso em 06 de junho de 2015. 